\title{
Successful surgical repair of a temporal and parietal bone fracture with associated traumatic brain injury in a fourteen-day-old foal
}

\author{
Succesvolle chirurgische behandeling van een os temporale en parietale fractuur met \\ bijhorende hersenschade bij een twee weken oud veulen
}

\author{
${ }^{1}$ H. Haardt, ${ }^{2}$ K. Vanderperren, ${ }^{3} \mathrm{C}$. Bauwens, ${ }^{3}$ L. Lefère, ${ }^{2}$ E. Raes, ${ }^{1}$ E. Pollaris, ${ }^{1}$ A. Martens \\ ${ }^{1}$ Department of Surgery and Anesthesiology of Large Animals, Faculty of Veterinary Medicine, \\ Ghent University, Salisburylaan 133, 8920 Merelbeke, Belgium \\ ${ }^{2}$ Department of Medical Imaging and Small Animal Orthopedics, Faculty of Veterinary Medicine, \\ Salisburylaan 133, 9820 Merelbeke, Belgium \\ ${ }^{3}$ Department of Large Animal Internal Medicine, Faculty of Veterinary Medicine, \\ Ghent University, Salisburylaan 133, 8920 Merelbeke, Belgium
}

hanna.haardt@ugent.be

\section{$\Lambda_{\text {bstract }}$}

A fourteen-day-old warmblood colt presented with severe neurological signs of unknown origin. The foal was recumbent and comatose, and showed spastic motion of the head. Computed tomography (CT) examination revealed multiple impression fractures to the left parietal and temporal bones, as well as traumatic brain injury. Three fragments of the temporal bone were dislocated into the cranial vault. The foal was surgically treated within 24 hours of presentation: the fragments were elevated and the largest fragment was fixated with an L-shaped titanium MatrixMidface $0.8 \mathrm{~mm}$ reconstruction plate. The brain injury resolved with medical treatment and supportive care. Apart from a localized wound abscess that was drained, postoperative healing was uneventful and the foal regained the ability to ambulate 18 days after surgery. Follow-up CT imaging documented good fracture healing and a favorable development of the soft tissue injuries. Seven months after surgery, the foal was fully recovered and showed no neurological signs.

\section{SAMENVATTING}

Een veertien dagen oud hengstenveulen werd aangeboden met ernstige zenuwsymptomen van onbekende oorsprong. Het veulen kon niet recht staan, was comateus en vertoonde spastische bewegingen van het hoofd. Op CT-onderzoek werd een multipele indeukingsfractuur van het linker os temporale en parietale vastgesteld alsook tekenen van traumatische hersenschade. Drie fragmenten van het schedeldak waren verplaatst in de schedelholte. Binnen de 24 uur werd het veulen chirurgisch behandeld. Een elevatie van de fractuurfragmenten werd uitgevoerd en het grootste fragment werd gefixeerd met een L-vormige titanium MatrixMidface $0,8 \mathrm{~mm}$ reconstructieplaat. Bijkomend werd voor de hersenschade een medicamenteuze en ondersteunende therapie opgestart. Op de ontwikkeling van een gelokaliseerd wondabces na verliep de heling gunstig en kon het veulen 18 dagen na de chirurgie opnieuw zelfstandig stappen. Op de CT-controleonderzoeken konden een goede fractuurheling en een geleidelijke normalisatie van de hersenschade worden vastgesteld. Zeven maanden na de behandeling was het veulen volledig genezen en waren er geen neurologische afwijkingen.

\section{BACKGROUND}

Head trauma is common, especially in young horses. Fractures of the skull are caused by horses falling backwards, collision with solid objects, and kicks
(Ramirez et al., 1998; Lim et al., 2013). The majority of fractures of the head involve the maxilla, mandibles, and frontal bones including the facial sinuses (Schaaf et al., 2008). Fractures involving the cranial cavity are less frequent and usually carry a poor prog- 
nosis. Neurological symptoms of various nature can occur when fragments become displaced and pressure is exerted on the brain (Ramirez et al., 1998; Tremaine, 2004).

Skull fractures are often underestimated on visual examination (Fürst, 2010) and impression fractures are especially hard to detect on palpation, because of the associated soft tissue swelling (Auer, 2019). To confirm the presence or absence of skull fractures, radiographs can be taken, but the extent of the fracture is nearly always underestimated (Crijns et al., 2019). Therefore, CT imaging is the diagnostic modality of choice offering valuable information for prognosis and for planning a surgical intervention (Ramirez et al., 1998; Beccati et al., 2011; Crijns et al., 2019).

Treatment options include stabilization of the patient with corticosteroids, diuretics, and mannitol, followed by either conservative treatment or surgery (Feary et al., 2007; Auer, 2019). Surgical treatment is warranted when the fracture is unstable or when fragments are displaced (Feary et al., 2007). Fracture stabilization with wires, sutures or plates has been described for equine facial and skull fractures (Dowling et al., 2001; McMaster et al., 2016; Derham et al., 2019).

To the authors' knowledge, this is the first case report describing the successful surgical treatment of a parietal and temporal bone fracture with associated traumatic brain injury.

\section{CASE HISTORY AND CLINICAL PRESENTA- TION}

A fourteen-day-old Belgian Warmblood colt was presented for the assessment and treatment of acute onset of severe neurological symptoms, as well as fever and mild respiratory symptoms. Two days before presentation, the foal showed an increased respiratory rate and was consequently treated with ceftiofur (dose unknown) by the owner, who is a veterinarian. In the evening prior to presentation, the owner found the deteriorating foal in the stable: it had suddenly become recumbent and stuporous and showed labored breathing. Flunixin Meglumine (Emdoka, Belgium) (1.1 $\mathrm{mg} / \mathrm{kg}$ BDW), Dexamethasone (Dechra, UK) (0.18 $\mathrm{mg} / \mathrm{kg}$ BDW) and Enrofloxacin (Bayer, Germany) $(3.6 \mathrm{mg} / \mathrm{kg}$ BDW) were administered by the owner and the foal was immediately transported to the clinic.

On presentation, the foal was recumbent, comatose, showed little movement of the extremities and spastic motion of the head. The muscle tone of the tongue was absent, and the pupillary reflex was decreased on both sides. All other clinical parameters were within normal limits. No abnormalities were appreciated upon visual examination and palpation of the head. Thoracic ultrasound revealed mild comet tailing in the right cranioventral lung field. Abdominal ultrasound was within normal limits.
On clinical pathology, the foal showed mild hypoproteinemia at $45 \mathrm{~g} / 1$ (reference range: $56-79 \mathrm{~g} / 1$ ), and decreased urea at $1.4 \mathrm{mmol} / 1$ (reference range: 3.6-8.9 $\mathrm{mmol} / \mathrm{l}$ ). All other values were within the reference range.

The foal was subsequently stabilized with fluid therapy (Ringer Lactate at $2.8 \mathrm{ml} / \mathrm{kg} / \mathrm{hr}, 30 \%$ Glucose at $1 \mathrm{ml} / \mathrm{kg} / \mathrm{hr}$ ), and mannitol (Baxter, UK) (1L 15\% mannitol solution QID), before further assessment the next morning.

Overnight, the patient regained the ability to stand, but conscious awareness remained completely absent. Analysis of the cerebrospinal fluid was within normal limits (WBC $0.37 \times 10^{\wedge} 9 / \mathrm{L}$, reference range $0-6 \times$ $\left.10^{\wedge} 9 / \mathrm{L}\right)$. Due to the persistence of the neurological symptoms without obvious cause, a CT scan of the head was performed.

\section{MEDICAL IMAGING}

The foal underwent a CT examination under general anesthesia in dorsal recumbency. The CT examination was performed using a 320-row scanner (Aquilion One, Canon Medical Systems, Tokyo, Japan). The following parameters were used for the CT image acquisition: slice thickness $0.5 \mathrm{~mm}$, rotation time $0.5 \mathrm{~s}$, pitch 0.638 , exposure settings $250 \mathrm{~mA}$ and $135 \mathrm{kV}, 512 \times 512$ matrix. A systemic bolus of $2 \mathrm{~mL} /$ $\mathrm{kg}$ of contrast medium (Iomeron 300, $300 \mathrm{mg}$ iodine/ $\mathrm{mL}$; Bracco Imaging SpA, Milan, Italy) was injected intravenously through the jugular vein using a power injector at a rate of $15 \mathrm{~mL} / \mathrm{s}$. The same CT protocol was repeated with an interval of 1 minute between administration and imaging. Bone and soft-tissue reconstructions were performed.

The CTscan revealed multiple sharply outlined transverse-oblique hypoattenuating fracture lines through the left lateral aspect of the cranial vault with involvement of the left parietal and temporal bones, creating two large elongated oval shaped fracture fragments and a smaller third fragment, at the ventral half of the temporal bone. All fracture fragments were mildly to moderately displaced medially into the cranial vault (Figures 1 and 2).

The dorsal fragment $(5 \times 2.3 \mathrm{~cm})$ was still attached rostrally at its base at the level of the frontoparietal suture. Towards caudally, the fragment was increasingly displaced intracranially creating a $10-\mathrm{mm}$ step at that level (Figure 2). Caudal to this step, a small fragment $(0.7 \times 1.2 \mathrm{~cm})$ was present at the ventral aspect of the temporal bone.

Ventral to this, a second large elongated fragment $(4 \mathrm{~cm} \times 1 \mathrm{~cm})$ was present with a partial interruption of the cortex at its ventral margin at the transition of the parietal to the left squamous part of the temporal bone. This fragment was mildly displaced intracranially.

In the parietal and temporal lobes of the left ce- 


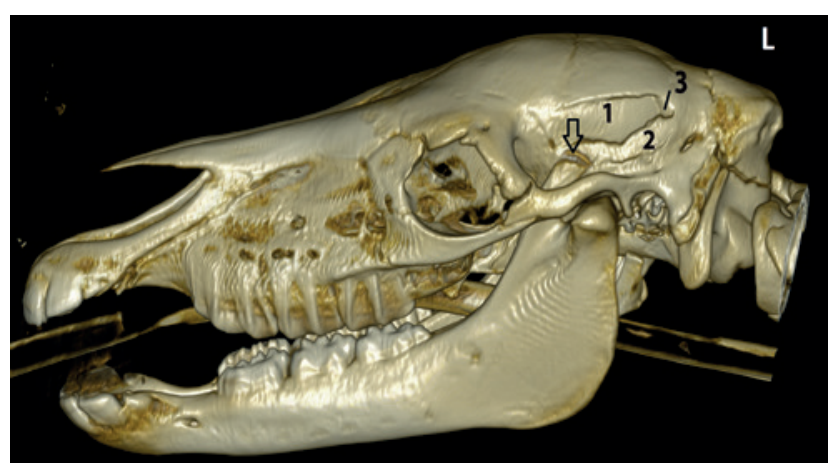

Figure 1. Preoperative computed tomographic images of the horse's head in $3 \mathrm{D}$ reconstruction. There is an impression fracture of the left temporal and parietal bone with a dorsal (1) and ventral (2) large elongated fragment. The small fragment (3) is located at the caudal edge of fragment 1 . The arrow indicates the coronoid fracture.

rebrum, bordering the fracture fragments, a large broad based semilunar shaped $(6 \mathrm{~cm} \times 3 \mathrm{~cm}$ x $4 \mathrm{~cm})$ mixed hypo- and hyperattenuating lesion, consistent with edema and hemorrhage was present. The latter caused a moderate mass effect recognized as a rightwards shift of the falx cerebri (midline shift) and compression of the caudal half of the left lateral ventricle (Figure 2). There was a concurrent swelling of the left temporal muscle with hyperattenuating lesion (hematoma) and the subcutaneous tissues.

Additionally, a zigzag-shaped, broad, hypoattenuating line was separating a small avulsion fragment (5 $\mathrm{mm} \times 1.8 \mathrm{~cm}$ ) at the dorsal aspect of the left coronoid process.

The final diagnosis was an acute traumatic injury with multiple depressed fractures of the left parietal and temporal bone with concurring intracranial hemorrhage and edema, and a hematoma in the left temporal muscle. In addition, there was a small avulsion fracture of the dorsal aspect of the left coronoid process.

\section{SURGERY}

Based on the CT images, it was decided to take the foal to surgery in order to reduce the displaced fracture and to stabilize the fragments.

The foal was anesthetized using a preanesthetic combination of fentanyl (Dechra, UK) $(9 \mathrm{mg} / \mathrm{kg}$ BDW i.v.) and midazolam (Le Vet Beheer, the Netherlands) $(0.11 \mathrm{mg} / \mathrm{kg}$ BDW i.v.), and induced with propofol (AST Farma, the Netherlands) $(8 \mathrm{mg} / \mathrm{kg}$ BDW i.v.). The foal was placed in right lateral recumbency, and anesthesia was maintained with sevoflurane in oxygen.

The surgical field was prepared in a routine manner. A $15-\mathrm{cm}$ medially based U-shaped skin incision was made starting at the rostral extent of the occipital bone to the supraorbital margin. The fracture was exposed by sharp dissection of the soft tissue and retraction of the temporalis muscle.

The dorsal fragment was reduced using a Hohman retractor and fixated to the parent bone using a titanium $2+3$ hole $0.8 \mathrm{~mm}$ thickness left L-plate designed for human craniomaxillofacial reconstruction (MatrixMIDFACE plate and screw system, Depuy Synthes, USA). The plate was fixated with two 1.5 $\mathrm{mm}$ diameter $\mathrm{x} 5 \mathrm{~mm}$ length screws on either side of the fracture line (Figure 3). The thickness of the bone, in which the screws were anchored, ranged from 2.89 to $3.96 \mathrm{~mm}$. The ventral fragment was then elevated

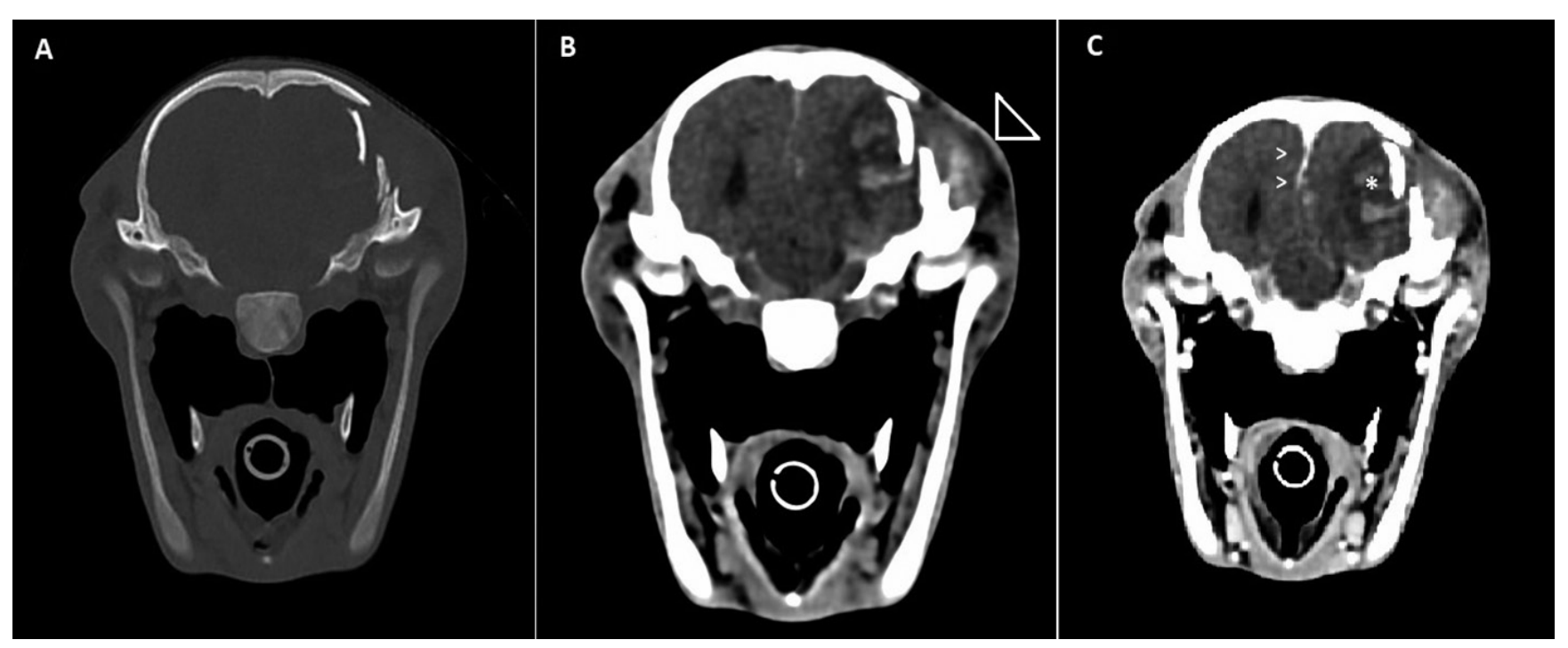

Figure 2. Transverse computed tomographic images of the foal's head showing the displacement of the fracture fragments in the cranial vault. Left side of the horse is on the right side of the images. A. Left and B. middle are native, C. the right image is acquired after intravenous contrast administration. A. is processed with bone filters, $B$. and $C$. with soft tissue filters. B. The arrowhead indicates the swelling of the subcutaneous soft tissues and the left temporal muscle with subcutaneous and intramuscular hematoma C. Arrowheads indicate the rightwards midline shift. Asterisk indicates the hemorraghe (hyperattenuating) surrounded by edema (hypoattenuating) of the brain. 


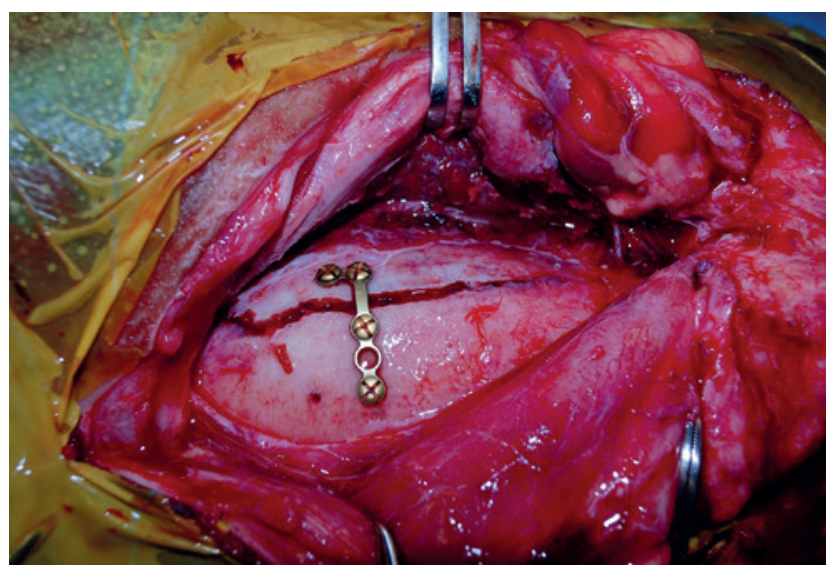

Figure 3. Intraoperative image after fixation of the dorsal temporal fragment with a L-shaped MatrixMIDFACE reconstruction plate and four screws.

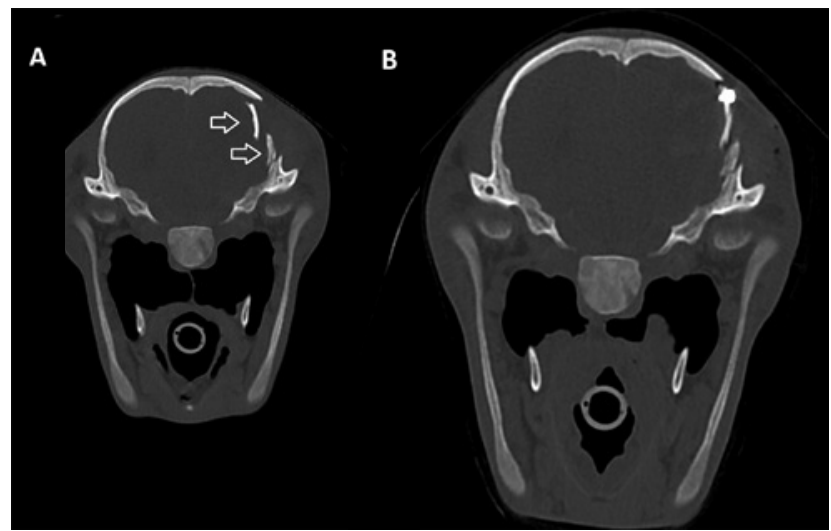

Figure 4. Transverse computed tomographic images of the foal's head at the level of fracture presented in a bone window. A. Preoperative image with two displaced fracture fragments (arrows) with the dorsal fragment most displaced intracranially. B. Immediate postoperative image after reduction and fixation of the dorsal large fragment with a reconstruction plate and screws. The tip of the screw slightly protrudes in the cranial vault.

above the dorsal fragment to create space and relief pressure on the brain, and did not require further stabilization.

The muscles, fascia, and subcutis were sutured in a simple continuous pattern with polyfilament absorbable suture (vicryl USP 2-0). The skin was closed in a simple continuous pattern with monofilament absorbable suture (monosyn USP 3-0). A sterile stent and an adhesive bandage were placed for recovery during the postoperative period.

The correct placement of the implants was confirmed with CT immediately postoperatively showing a much better, though not perfect, apposition of the dorsal elongated fragment (Figure 4). The four screws were slightly protruding on the medial side of the bony fragments.

The foal recovered from anesthesia uneventfully.

\section{POSTOPERATIVE PERIOD}

During the first 48 hours post-surgery, the foal was treated with midazolam (CRI, adjusted according to effect) to avoid excitement and promote calm behavior, as well as a tapering dose of dexamethasone and butorphanol for pain relief and to reduce inflammation. In addition, the foal was administered broad spectrum antibiotics for five days (Sodium-Penicillin, Kela, Belgium, 22000 IU/kg BDW TID, amikacin, Merial, France, $30 \mathrm{mg} / \mathrm{kg}$ BDW SID) and NSAIDs for 9 days (Ketofen, Ceva, France, $1.1 \mathrm{mg} / \mathrm{kg}$ BDW BID). Mannitol was discontinued five days after surgery. The fluid therapy was tapered and then discontinued ten days after surgery.

For the first three days post-surgery, the foal was kept in a recumbent position to avoid further head trauma and excitation. It received parenteral nutrition, and was turned every two hours. It slowly regained the ability to swallow two days post-surgery. At this point, refeeding with the mare's milk and administration of Gaviscon (Reckitt Benckiser Healthcare, Belgium) (260 mg sodium alginate QID) was initiated. The foal remained unable to nurse, and was fed with a bottle. The colt was then transitioned to feeding from a bucket, which he tolerated well.

Eight days after surgery, a localized abscess developed at the rostral end of the incision. A bacteriologic sample was taken and submitted for culture and sensitivity testing. The abscess was drained at its most distal point, and the cavity was flushed daily with a $0.05 \%$-chlorhexidine solution. While awaiting the results, treatment was initiated with oral antibiotics (Trimethoprim-Sulfadiazine, TMPS, Emdoka, Belgium, $30 \mathrm{mg} / \mathrm{kg}$ BDW). Enterococcus faecalis was isolated, which showed intermediate sensitivity to TMPS. Due to the positive response to the antibiotic treatment prior to receiving the results, the antibiotic treatment regime was left unchanged. The abscess responded well to treatment, and resolved within seven days. The antibiotic treatment was discontinued after ten days.

Eighteen days after surgery, the foal had stabilized to a degree that allowed hand-walking and subsequent turnout in a small paddock.

CT examination was repeated at 26 and 54 days post-surgery and showed favorable development of the lesions (Figures 5A, B, C): on the post-operative $\mathrm{CT}$ scan at 26 days post-surgery, the area of the mixed hematoma and edema seen in the pre-operative scan, had developed into two oval shaped hypodense regions adjacent to the skull fracture fragments surrounded by a thin, well-defined, hyperattenuating rim post-contrast administration (Figure 5B). The center of these regions was very mildly hypoattenuating in relation to the surrounding white matter. No mass effect was present. Radiologically, these areas were suspected to be a resolving previously infected hematoma, or less likely a brain abscess. In the absence of clinical signs of infection, this could not be confir- 


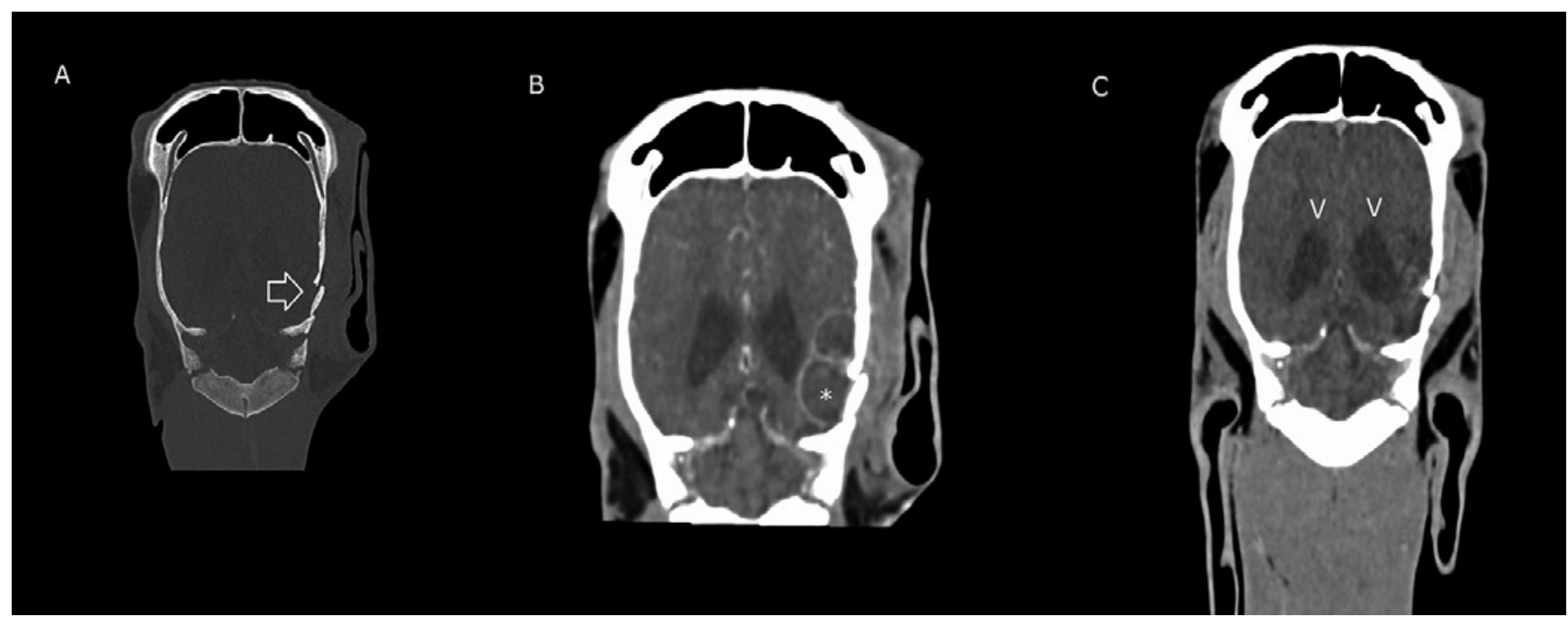

Figure 5. Dorsal reconstructed computed tomographic images of the foal's head. The fracture is indicated with arrows. A. 26 days post-surgery, native, bone window. B. 26 days post-surgery, with contrast, soft tissue window, bilobular appearance of a resolving hematoma and rim enhancement (asterisk) C. 54 days post-surgery, with contrast. The hematoma is resolved. The ventricles (arrowheads) are mildly enlarged (left more pronounced than right).

med. At 54 days post-surgery, the lesion was no longer present (Figure 5C). The left parietal/temporal lobe adjacent to the fracture remained hypodense in relation to the normal brain parenchyma. The last CT examination confirmed good position of the implants without signs of implant failure or loosening. Mild callus formation of the left parietal/temporal bone fractures was visible. There was a mild increased ventriculomegaly (left $>$ right). The coronoid process fracture was healed.

Two days after the last CT scan, the foal was discharged to the owner.

Follow-up was conducted seven months after surgery via phone and the evaluation of videos of the foal provided by the owner. The cosmetic outcome was excellent with the scar no longer being visible (Figure 6 ). The foal was fully functional, developing well and did not show any neurological signs.

\section{DISCUSSION}

Fractures of the equine skull are relatively common in horses and most frequently involve the mandibula, maxilla, as well the orbital rim, frontal, nasal, and lacrimal bones (Fürst, 2010). Fractures of the occipital, parietal and temporal bones resulting in damage to the central nervous tissue are much less frequent and to the authors' knowledge, successful surgical treatment has not been described yet. Depending on the location of the skull fracture, horses can show bleeding or leakage of cerebrospinal fluid out of various orifices or into the sinuses and guttural pouches (Fürst, 2010; Beccati et al., 2011). When the cranium is affected, the fractures can be complicated by severe damage to the underlying structures (Ramirez et al., 1998). Nevertheless, damage to the central nervous system is uncommon (Beccati et al., 2011).

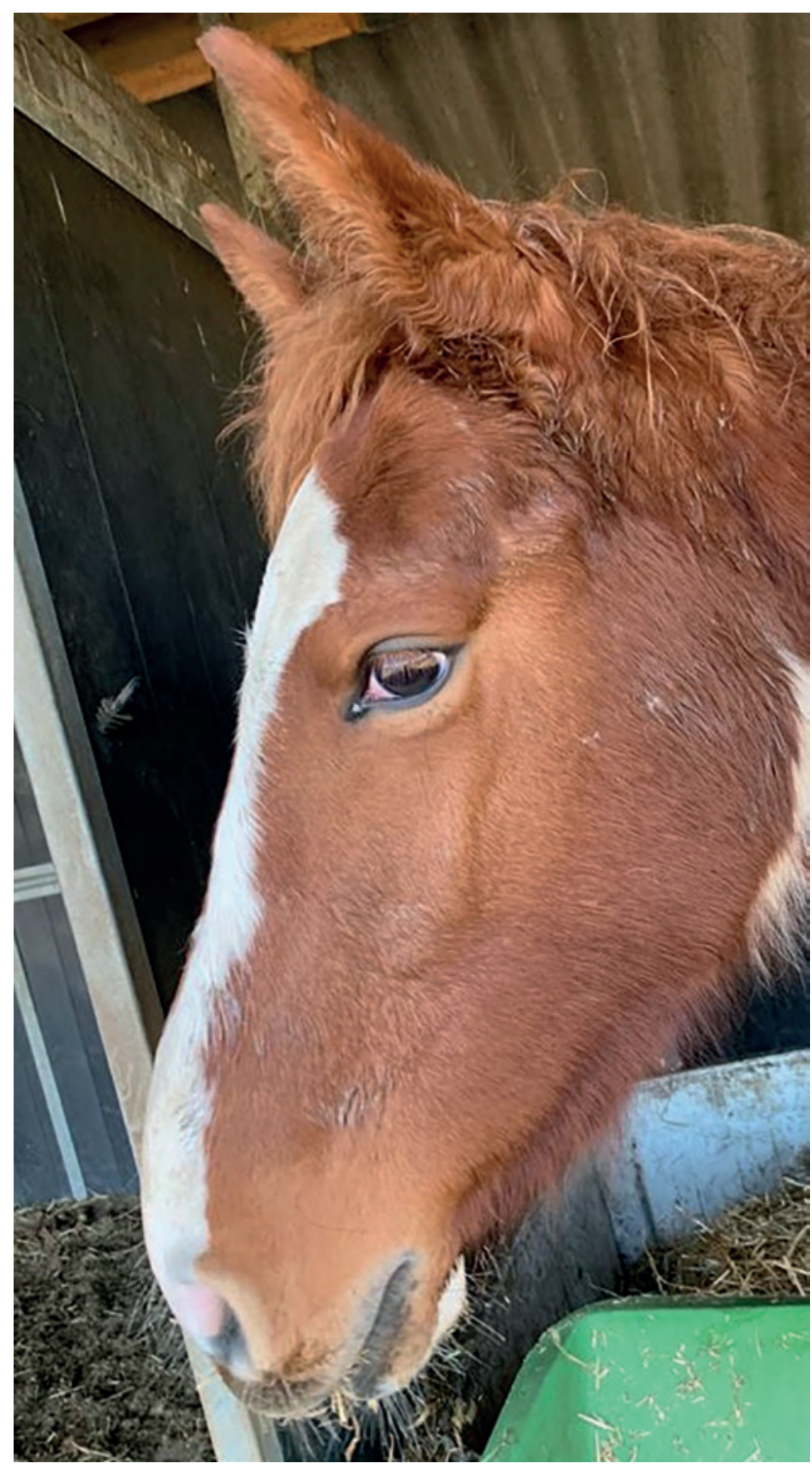

Figure 6. Seven months post-surgery. The cosmetic outcome is excellent (Picture taken by the owner). 
In the present case, there was no known history of trauma, and clinical examination revealed neither wounds on the head nor bleeding. Nevertheless, the foal's symptoms were consistent with traumatic brain injury. Intracranial hemorrhage or other space occupying lesions can cause alterations in mentation (Fürst, 2010). Stupor and coma, as well as changes in breathing pattern, which the colt displayed, are symptoms of forebrain injury. Trauma to the pons and medulla and hindbrain trauma can cause tongue paralysis when the XII cranial nerve (hypoglossal nerve) is damaged (Feary et al., 2007). To further evaluate the nature of the disease, a cerebral spinal fluid tap was conducted and was found to be negative for signs of infection.

Even though radiography is more readily available as a diagnostic tool in practice, it is not very sensitive to detect skull fractures, because of the overlap of many structures (Beccati et al., 2011; Lim et al., 2013; Crijns et al., 2019). The different imaging modalities for fractures of the skull are well described, and there is a consensus that CT imaging is the most sensitive (Ramirez et al., 1998; Beccati et al., 2011; Crijns et al., 2019). In this case, CT allowed a complete and accurate evaluation of the extent of the fractures, the degree of displacement and the impact of the fracture fragments on the brain. Additionally, it allowed the recognition of traumatic fragmentation of the coronoid process, even though specific treatment was not considered necessary for this lesion.

For assessment of traumatic brain injury in humans, CT examinations are the first line diagnostic modality in a trauma setting. Its availability, ability to detect hemorrhagic injury, such as strokes and bleeding, and fast results make it more suitable than MRI for immediate imaging post-injury (Mutch et al., 2016; Schweitzer et al., 2019). Similarly to humans, the longer duration of MRI examination compared to a CT limits the use of MRI immediately after suspected traumatic brain injury (Holmes, 2014; Carmalt et al., 2015). Nevertheless, MRI is more sensitive for certain intracranial injuries such as axonal injuries (Schweitzer et al., 2019). This difference can be attributed to the different principle of image acquisition. In contrast to CT, which can only detect morphological changes, MRI displays pathology based on changes in tissue signal intensity, thus making more lesions detectable (Holme, 2014). To overcome this, contrast medium is used in CT imaging. With contrast enhanced CT (CECT), the principle of increased attenuation is used to show differences in vascularization and vascular permeability. This makes CECT less dependent on morphological changes (Crijns et al., 2016). However, Lacombe (2010) reported that CECT could only find lesions that were not evident on $\mathrm{CT}$ in one out of eight cases.

In general, head fractures not involving the cranium have a good prognosis, even when they are severely displaced. This is due to good vascularization and little force working on the bones (Fürst, 2010).
However, the prognosis for patients showing neurological signs is typically considered poor (Ramirez et al., 1998). Tremaine (2004) suggested euthanasia for cases that show significant neurological signs. In a study by Feary et al. (2007), horses that remained recumbent for more than four hours after initiation of treatment, were found to have a worse prognosis, although this may be related to the complications posed by an adult horse remaining in recumbency. The onset of neurologic symptoms can either be peracute or delayed, depending on the mechanism of injury. Delayed symptoms can be caused by dislocation of fragments or callus formation (Ramirez et al., 1998). In this case, CT revealed multiple traumatic depressed fractures of the left parietal and temporal bone with displacement into the cranial vault. These and the intracranial hemorrhage and edema have likely caused the central nervous symptoms of the colt.

In cases of severe neurologic symptoms, stabilization of the patient should be prioritized (Ramirez et al., 1998; Feary et al., 2007; Fürst, 2010; Auer, 2019). Initial treatment should include fluid therapy, corticosteroids and mannitol to decrease the intracranial pressure, reduce inflammation, and to reverse symptoms caused by shock (Feary et al., 2007; Fürst, 2010). Immediate surgical intervention is discouraged, as severe soft tissue swelling can hinder the fracture repair (Auer, 2019). Fürst (2010) discourages surgical intervention for fractures of the cranium, unless the case is likely to benefit from an intracranial decompression or reduction of the fracture. It has been mentioned that careful surgery is indicated when fragments are dislocated and impinging on the cerebral cortex (Feary et al., 2007).

The foal responded well to initial therapy, to a degree at which general anesthesia and surgery were deemed safe. There is little information in the literature on how to address fractures of the calvarium. In humans, elevation of depressed skull fractures is indicated when there is bone displaced more than the full thickness of the skull (Gruen, 2002). Although extrapolation of surgical techniques and guidelines have to be done carefully, due to the severe displacement (10 $\mathrm{mm}$ ) of a fracture fragment in this case, it was deemed to be necessary to surgically intervene. Nevertheless, there is plenty of information about fracture fixation in the facial skull and the jaw. Fragments of impression fractures must be elevated before fixation. Small fragments that are not covered by periosteum should be removed. In some cases, the serrated surfaces of the bone fragments make fracture fixation with implants redundant (Fürst, 2010). This was the case for the smaller, ventral fragment of the foal's fracture in the present case. If further fixation is required, the surgeon has several options. When the adjacent bone is stable, a USP 2-polydioxanon suture can be used to avoid implants and the complications associated with them (Schaaf et al., 2008; Fürst, 2010). When a more rigid fixation method is needed, e.g. in comminuted 
fractures, different plates can be used (Dowling et al., 2001; McMaster et al., 2016; Derham et al., 2019).

In the field of human craniomaxillofacial, reconstructive surgery titanium implants are the gold standard. Titanium is highly stable, yet pliable and lightweight (Schumann et al., 2013). It has a lower modulus of elasticity than stainless steel and has unique biocompatibility properties (Meslemani and Kellman, 2012). The use of titanium implants in equine surgery is however very limited due to their higher price and lower stress resistance. In contrast to facial fracture repair, osteosynthesis of the calvarium is restricted to screw sizes that do not exceed the bone width in order to avoid compression of the underlying nervous tissues. Thus, a 'miniplate' and screw commonly used in human midface fracture repair was used in the present case (Wiltfang, 2002). The length of the available screws used in the colt slightly exceeded the width of the bone. Although this is not optimal, no negative effects were noted in this case. To the authors' knowledge, this is the first case report of a successful fracture repair of a temporal bone fracture with concurrent traumatic brain injury. Despite the poor prognosis reported in the literature for head trauma evoking neurological symptoms, the colt could be treated with surgical fracture repair and supportive care. Due to the close proximity to the underlying neural tissues, a thin $(0.8 \mathrm{~mm})$ titanium plate with accompanying short $1.5 \mathrm{~mm}$ diameter screws, designed for human craniomaxillofacial reconstructive surgery, was used to avoid impingement on the brain.

$\mathrm{CT}$ imaging provided sufficient detail of osseous and soft tissue trauma for surgical planning, as well as for monitoring of the healing process.

The foal made a full recovery, and no longer showed any signs of neurological disease at seven month post-surgery.

\section{REFERENCES}

Auer, J. A., Stick, J. A., Kümmerle, J. M., Prange, T. (2019). Equine Surgery. Fifth edition, W.B. Saunders, Philadelphia, p. 1794-1829.

Beccati, F., et al. (2011). Comminuted basilar skull fracture in a colt: Use of computed tomography to aid the diagnosis. Equine Veterinary Education 23(7), 327-332.

Carmalt, J. L., Montgomery J. (2015) Intraarterial injection of iodinated contrast medium for contrast enhanced computed tomography of the equine head. Veterinary Radiology \& Ultrasound 56(4), 384-390.

Crijns, C. P., et al. (2016). Intra-arterial versus intra venous contrast-enhanced computed tomography of the equine head. Bmc Veterinary Research 12, 6.

Crijns, C. P., et al. (2019). Comparison between radiography and computed tomography for diagnosis of equine skull fractures. Equine Veterinary Education 31(10), 543-550.

Derham, A. M., et al. (2019). Surgical repair of a depressed, comminuted fracture of the zygomatic process of the frontal bone using a locking compression plate in a Thoroughbred colt foal. Clinical Case Reports 7(1), 110-114.

Dowling, B. A., Dart A. J., Trope G. (2001). Surgical repair of skull fractures in four horses using cuttable bone plates. Australian Veterinary Journal 79(5), 324-327.

Feary, D. J., et al. (2007). Traumatic brain injury in horses: 34 cases (1994-2004). Javma-Journal of the American Veterinary Medical Association 231(2), 259-266.

Fürst, A., Jackson, M., Kümmerle, J., Bettschart-Wolfensberger, R., Kummer, M. (2010). Übersicht über die aktuellen Therapiemöglichkeiten der Frakturen am Kopf des Pferdes. Pferdeheilkunde 26(4), 503-514.

Gruen, P. (2002). Surgical management of head trauma. Neuroimaging clinics of North America 12, 339-343.

Holmes, S. P. (2014). Equine skull magnetic resonance imaging: The where, when and why? Equine Veterinary Education 26(11), 605-609.

Lim, C. K., et al. (2013). Basilar skull fracture in a Thoroughbred colt: radiography or computed tomography? Journal of the South African Veterinary Association 84(1), E1-5.

McMaster, M., et al. ( 2016). Reconstruction of a complicated orbital depression fracture with medial wall and globe repositioning in a horse: a collaboration across disciplines and specialties. Veterinary Surgery 45(4), 529535.

Meslemani, D., Kellman R. M. (2012). Recent advances in fixation of the craniomaxillofacial skeleton. Current Opinion in Otolaryngology \& Head and Neck Surgery 20(4), 304-309.

Mutch, C. A., Talbott J. F., Gean A. (2016). Imaging evaluation of acute traumatic brain injury. Neurosurgery Clinics of North America 27(4), 409-439.

Ramirez, O., Jorgensen J. S., Thrall D. E. (1998). Imaging basilar skull fractures in the horse: a review. Veterinary Radiology \& Ultrasound 39(5), 391-395.

Schaaf, K. L., Kannegieter N. J., Lovell D. K. (2008). Management of equine skull fractures using fixation with polydioxanone sutures. Australian Veterinary Journal 86(12), 481-485.

Schumann, P., et al. (2013). Perspectives on resorbable osteosynthesis materials in craniomaxillofacial surgery. Pathobiology: Journal of Immunopathology, Molecular and Cellular Biology 80(4), 211-217.

Schweitzer, A. D., et al. (2019). Traumatic brain injury: imaging patterns and complications. radiographics: a review publication, Radiological Society of North America, Inc 39(6), 1571-1595.

Tremaine, H. (2004). Management of skull fractures in the horse. In Practice 26(4), 214.

Wiltfang, J. (2002). Osteosynthesis in craniomaxillofaxial surgery. Hno 50(9), 800-811.

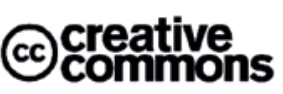

C) 2021 by the authors. Licensee Vlaams Diergeneeskundig Tijdschrift, Ghent University, Belgium. This article is an open access article distributed under the terms and conditions of the Creative Commons Attribution (CC BY) license (http://creativecommons.org/licenses/by/4.0/). 